\title{
Does Vascular Elasticity Affect Arteriovenous Fistula Maturation?
}

\author{
William D. Paulson*
}

Specialty Care, Charlie Norwood VA Medical Center, and Section of Nephrology, Department of Medicine, Georgia Regents University, Augusta, Georgia, USA

\begin{abstract}
The vasculopathy of ESRD affects both arteries and veins. The arteries develop arteriosclerosis, which is largely a disease of the media characterized by increased collagen content, calcification, and both hypertrophy and hyperplasia of vascular smooth muscle cells. Veins may exhibit increased width of the intimal and medial layers, and may develop neointimal hyperplasia and calcification. Successful fistula maturation depends upon dilatation and remodeling of the artery and vein, but the stiff and thickened vessels of ESRD patients may respond poorly to signals that promote these adaptations. There is intense interest in accurately predicting fistula maturation outcome and preventing maturation failure. However, definitive criteria for preoperative testing of vessel elasticity have not yet been established. Tests that are adopted for widespread clinical use will need to be easy to apply - a standard that many of these tests may not meet. Finally, effective treatments are needed that prevent or reduce the stiffness of vessels. In conclusion, although there are many promising developments in this emerging field, effective methods of predicting fistula maturation outcome and preventing maturation failure remain to be established.
\end{abstract}

Keywords: Arterial stiffness, arteriosclerosis, arteriovenous fistula, calcification, dialysis access, hemodialysis, vascular access, venous distensibility.

\section{INTRODUCTION}

Failure of native arteriovenous fistulas continues to be a major unsolved problem. Although mature fistulas survive longer than grafts, this advantage largely disappears when the two types of access are compared from the time of surgical creation [1-3]. Moreover, in the DAC multicenter randomized controlled trial, $61 \%$ of fistulas failed to mature sufficiently to be used for dialysis [4]. Thus, methods of predicting fistula maturation outcome and preventing maturation failure are under intense investigation. The causes of maturation failure can be divided into 4 general categories (Fig. 1): 1. Surgical skill, experience and patient selection; 2. Pre-existing vascular disease; 3. Upstream events; and 4. Downstream events. Upstream events are the mechanisms that initially cause injury to the endothelium (surgical trauma, hemodynamic shear stress, vessel wall injury caused by needle punctures, etc.) [5]. Downstream events are the responses to endothelial injury (leukocyte adhesion, migration of smooth muscle cells from the media to the intimal layer, smooth muscle proliferation, etc.) [6]. The figure emphasizes that although upstream and downstream events are important steps in maturation failure, pre-existing vascular disease should not be neglected as it sets the stage for what follows. This review will address the influence of pre-existing vascular disease on maturation.

\section{THE VASCULOPATHY OF ESRD}

Atherosclerosis and arteriosclerosis are the major causes of cardiovascular disease in ESRD (Fig. 2), but arteriosclerosis

*Address correspondence to this author at the Department of Medicine, Georgia Regents University, 1120 15th Street, Augusta, GA 30909, USA; Tel: 706-721-2861; Fax: 706-721-7136; E-mail:wpaulson@gru.edu
Surgical skill, experience, patient selection $\downarrow$

Pre-existing vascular disease $\downarrow$

Upstream events

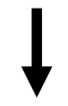

\section{Downstream events}

Fig. (1). The four categories that explain the causes of fistula maturation failure.

probably accounts for the bulk of cardiovascular deaths [7-10]. Atherosclerosis is an intimal disease characterized by plaques and occlusive lesions, and is the accepted cause of most of the vascular diseases in the general population. In contrast, arteriosclerosis in ESRD is largely a disease of the medial layer characterized by increased collagen content, calcification, and both hypertrophy and hyperplasia of vascular smooth muscle cells [7, 9, 11-13]. These changes result in increased thickness and stiffness of the arterial wall. ESRD patients develop cardiovascular complications that far exceed what would be expected from traditional risk factors alone [14]. Arteriosclerosis fills the gap and can be considered to be the vasculopathy of ESRD. Concomitant 
presence of diabetes mellitus can contribute to these abnormalities through accumulation of inelastic material in the arterial wall [15].

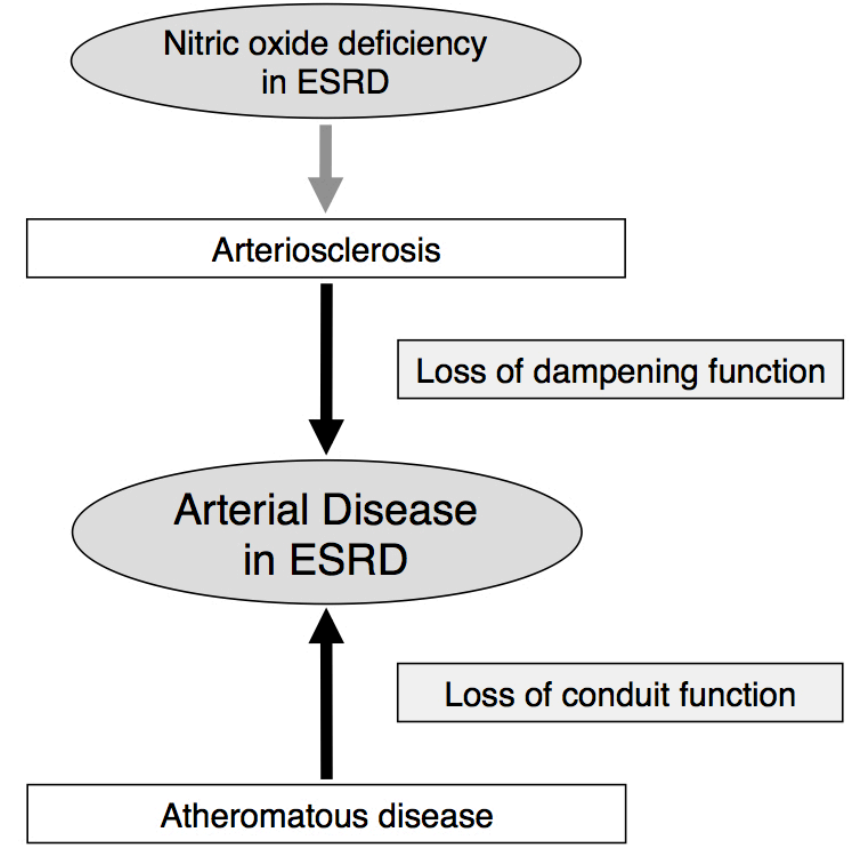

Fig. (2). The two major causes of vascular disease in ESRD. Nitric Oxide deficiency may play an important role in fistula maturation failure.

The increased arterial stiffness of arteriosclerosis yields high systolic and pulse pressures $[9,10,16]$. These hemodynamic changes are caused by the loss of dampening function of arteries, which promotes an increase in pulse wave velocity. In a normal vascular circuit, arterial pulse waves are reflected back from the periphery and branch points, and these reflected waves ordinarily augment diastolic pressure and thereby enhance coronary perfusion. However, when pulse waves travel more quickly, reflected waves may return during systole, thereby augmenting systolic pressure and reducing diastolic pressure. Arteriosclerosis helps explain the enhanced structural heart disease in ESRD, which leads to complications such as congestive heart failure, arrhythmias, and sudden death [17-20].

There has been a growing realization that the vasculopathy of ESRD is not restricted to the artery. When Feinfeld et al. examined veins of hemodialysis patients that had not been used for creation of a vascular access, they found that the widths of the intimal and medial layers were increased [21]. Moreover, neointimal hyperplasia and calcification have been documented in veins prior to access surgery [22-24]. Thus, the vasculopathy of ESRD appears to be general, and approaches to solve the problem of maturation failure may need to address both arteries and veins.

\section{ROLE OF DILATATION IN FISTULA MATURATION}

Inflammation, endothelial dysfunction, and nitric oxide deficiency are major causes of the arterial stiffness that contributes to fistula maturation failure [25-29]. Nitric oxide activates guanylate cyclase, which increases the level of cyclic guanosine monophosphate (cGMP). cGMP then induces vascular smooth muscle relaxation, which causes vessels to dilate. Thus, lack of nitric oxide impairs vessel dilatation, which may lead to maturation failure because dilatation of the anastomosed artery and vein is the key step in fistula maturation.

The stiff, thickened and calcified vessels of dialysis patients may not respond well to signals such as nitric oxide that promote dilatation. Inadequate dilatation and remodeling of a fistula may yield a vein with a luminal diameter that is too small for repeated cannulation by dialysis needles. Since the artery is generally narrower than the vein, the artery is the chief source of vascular resistance in a new fistula. Thus, arterial dilatation also appears to be a key step in maturation.

Fistula maturation begins with creation of the artery-vein anastomosis, which causes an increase in flow and shear stress. Increased shear stress then promotes release of nitric oxide, which ideally causes dilatation of the artery and vein so that shear stress returns toward pre-fistula levels [30, 31]. The increased pressure in the vein also promotes dilatation and remodeling (medial hypertrophy). Thus, adequate elasticity and nitric oxide are necessary for vessel dilatation during fistula maturation.

However, arteriosclerosis impairs the arterial elasticity that is necessary for dilatation $[9,12,13,16]$, and endothelial dysfunction with reduced nitric oxide production further impairs vasodilatation [25-29]. Thus, ESRD patients have poor nitric oxide-dependent flow mediated dilatation [32]. Also, most failed fistulas develop stenosis at the artery-vein anastomosis or downstream in the outflow vein. Stenosis is believed to be caused by low or oscillatory shear stress and turbulent flow [33, 34], which may be enhanced in the absence of dilatation. It follows that increased arterial stiffness and reduced nitric oxide can be expected to play key roles in maturation failure.

Preoperative duplex ultrasound mapping of vessels has been used to establish minimal acceptable diameters when evaluating patients for fistula creation. The recommended minimal diameters have varied from study to study, but the most widely accepted values for the artery and vein are generally 2.0 and $2.5 \mathrm{~mm}$, respectively [35]. Unfortunately, the success of mapping has been mixed, and has done little to improve maturation rates $[4,36]$. Nevertheless, smaller luminal diameters are a dilatation challenge that is generally best avoided.

Preoperative ultrasound measurement of vessel diameters has had limited benefit in improving maturation in part because diameter alone does not determine the suitability of a vessel. Rather, the key to suitability is the ability of the vessel to dilate in response to an increase in shear stress. A contributing factor is that ultrasound is observer dependent and may lack adequate reproducibility [37]. Consequently, there has been growing interest in preoperative testing of vessel function (i.e. elasticity) in the hope that this will provide an adequate estimate of a vessel's ability to dilate [38].

\section{DEFINITIONS OF INDICES OF ELASTICITY (STIFFNESS)}

The general properties of arteries vary depending upon their diameter, location, and content of elastin, collagen, and 
smooth muscle. We are concerned here with the smaller peripheral muscular arteries, such as the brachial and radial arteries. Definitions of stiffness are complex because the arterial wall is not homogeneous, and elastic properties vary depending on a number of factors, including the distending pressure and vessel diameter. Thus, a number of indices for measuring stiffness have been developed, and these can be a source of confusion. For example, compliance and distensibility may seem to be synonymous, but they are not so in the nomenclature of this field [39, 40]. Arterial compliance is defined as the change in diameter of an artery $(\Delta \mathrm{D})$ divided by the increase in pressure $(\Delta \mathrm{P}): \Delta \mathrm{D} / \Delta \mathrm{P}$. On the other hand, arterial distensibility measures arterial compliance relative to vessel diameter: $(\Delta \mathrm{D} / \mathrm{D}) / \Delta \mathrm{P}$. This distinction is important because different components of the vessel wall are recruited for stretching as the diameter increases, and this changes the measured compliance or distensibility.

In this review, we will use terms such as elasticity, stiffness, compliance, and distensibility interchangeably according to the terminology of authors, many of whom do not apply the formal definitions of indices. Excellent reviews are available that explain the indices and their physiology $[39,40]$.

\section{TESTING VESSEL ELASTICITY}

There is a growing literature on methods of measuring elasticity of arteries and veins, a number of which are listed in Table 1 [40, 41]. Although most of these methods have correlated with maturation outcome, studies have generally been limited by their small size and scope, and results among various researchers have not always been consistent. Thus, no definitive criteria for applying tests of elasticity have been established in this emerging field. Tests that are adopted for widespread clinical use will need to be easy to apply - a standard that many of these tests do not meet.

Application of a tourniquet to the proximal arm has been used to test the ability of a vein to dilate [42]. In this method, proximal (downstream) pressure on the vein is incrementally increased by tightening the tourniquet and the increase in luminal diameter is measured by ultrasound at each step. The tourniquet method of measuring distensibility has correlated with maturation outcome [43-45]. An alternative method of promoting vein dilatation is by warm water immersion [46]. Measurement of forearm venous distensibility by straingauge plethysmography has also correlated with maturation outcome [47]. In a novel approach, finite element analysis has been combined with ultrasonography to measure vein compliance [48].

Lok et al. have developed criteria for estimating risk of maturation failure based upon clinical factors [49]: age $>65$ years old, presence of peripheral vascular disease or coronary artery disease, and black race. It seems likely that Lok's criteria are a largely surrogates for arterial stiffness, which suggests that more specific measures of stiffness may be even more useful.

Aortic pulse wave velocity measurements have long been the gold standard in measuring arterial stiffness [41]. This method is conceptually easy as it measures the difference in time of travel to two different points in the arterial system (e.g. carotid and femoral arteries). The difference in distance traveled divided by time is the pulse wave velocity. The cardio-ankle vascular index is a modification of pulse wave velocity that is intended to improve measurement of arterial stiffness by adjusting for the effect of blood pressure on velocity [50]. The ongoing Hemodialysis Fistula Maturation Study may help establish the value of pulse wave velocity in predicting maturation outcome [51].

Table 1. Methods of measuring vessel elasticity or distensibility that may help predict fistula maturation outcome.

\begin{tabular}{|c|c|}
\hline Testing Method & References \\
\hline \multicolumn{2}{|l|}{ Vein } \\
\hline Application of tourniquet (diameter by duplex ultrasound) & {$[42-45]$} \\
\hline Warm water immersion (diameter by duplex ultrasound) & [46] \\
\hline Strain-gauge plethysmography & [47] \\
\hline Finite element analysis combined with duplex ultrasound & [48] \\
\hline \multicolumn{2}{|l|}{ Artery } \\
\hline $\begin{array}{l}\text { Lok Criteria (age, peripheral vascular disease, coronary } \\
\text { artery disease, race) }\end{array}$ & [49] \\
\hline Aortic pulse wave velocity & [41] \\
\hline Cardio-ankle modification of pulse wave velocity & [50] \\
\hline High resolution ultrasound speckle-tracking algorithms & {$[38,52]$} \\
\hline Elastic modulus by duplex ultrasound & {$[53]$} \\
\hline Photoplethysmography & {$[54]$} \\
\hline Flow mediated dilatation of brachial artery & {$[55]$} \\
\hline $\begin{array}{l}\text { Resistance index measured during fist relaxation after } \\
\text { fist clenching }\end{array}$ & {$[36,43,45]$} \\
\hline Small artery elasticity index by tonometer & {$[56-58]$} \\
\hline
\end{tabular}

The feasibility of applying other measures of elasticity in ESRD has been explored. High resolution ultrasound speckle-tracking algorithms have been used to measure arterial compliance [38, 52]. Duplex ultrasound has been used to measure the elastic modulus of the brachial artery, which is inversely related to arterial elasticity [53]. Finally, the digital volume pulse is a noninvasive method of assessing arterial stiffness that uses photoplethysmography to analyze the contour of the digital pulse [54]. The effectiveness of these methods in predicting maturation outcome remains to be tested.

Studies that have tested the influence of flow-mediated dilatation on fistula outcomes have had some success. Flow mediated dilatation of the brachial artery has correlated with the increase in arterial and venous diameter at 3 months after fistula creation [55]. In flow mediated dilatation, ischemia is induced with a tourniquet applied to the arm. Release of the tourniquet causes dilatation of arterioles, which increases brachial artery blood flow. The higher flow then yields an increase in shear stress, which induces nitric oxide release and brachial artery dilatation. It should be realized, however, that the method depends upon reactive vasodilatation induced by ischemia, and is therefore not strictly equivalent to measuring arterial stiffness or response to nitric oxide per se. 
A similar approach uses fist relaxation after sustained fist clenching. This produces transient arteriole dilatation of the distal hand that is similar to the mechanism of flow-mediated dilatation. Malovrh found that resistance index and blood flow before and after fist clenching correlated with successful maturation [43], but resistive index did not in two other studies [36, 45].

\section{ROLE OF SMALL ARTERY ELASTICITY INDEX}

The HDI/PulseWave CR-2000 System (Hypertension Diagnostics, Inc., Eagan, MN) provides a measure of small artery and large artery elasticity index [56, 57]. The instrument uses a noninvasive tonometer to perform pulse contour analysis of radial artery waveforms, and easily yields a measurement in approximately 5 minutes. The only practical limitation is that the vascular system in the arm should not be altered by surgery or other major abnormalities.

We previously used this device to test the hypothesis that these measures of elasticity correlate with fistula maturation outcome [58]. On the day of fistula surgery, 32 patients underwent preoperative measurement of arterial blood pressure, and small and large artery elasticity indexes. Fistulas were considered mature if they were used successfully in 3 consecutive treatments within 6 months of surgery. Six fistulas were excluded from analysis of maturation because dialysis did not begin within 6 months.

Six out of 26 remaining fistulas failed to mature, and all 6 developed stenosis at the arteriovenous anastomosis. Average small artery elasticity index was lower in failed than in matured fistulas $(3.71 \pm 0.29( \pm \mathrm{SE})$ vs $2.25 \pm 0.33 \mathrm{ml} / \mathrm{mmHg} \times 100, \mathrm{P}=0.02$ ) (Fig. 3A), but there was no significant difference in large artery elasticity index. Both groups had low elasticity when compared with published control groups. For example, Prisant et al. [56] previously obtained an average small artery elasticity index of $7.0 \mathrm{ml} / \mathrm{mmHg} \times 100$ in a normal control group.

(A)

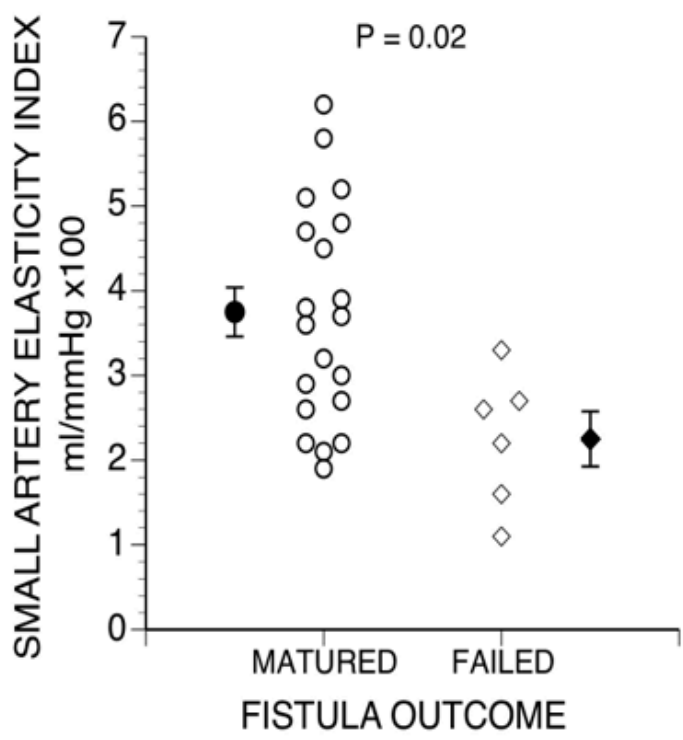

We used multivariable logistic regression analysis to analyze the risk of maturation failure [58]. We found that lower small artery elasticity index $(\mathrm{P}=0.008)$ (Fig. 3B and lower body mass index $(\mathrm{P}=0.02)$ were independent predictors of maturation failure. Lower body mass index may have favored failure because it was associated with smaller vein diameter $\left(\mathrm{R}^{2}=0.158, \mathrm{P}=0.04\right)$. Another contributing factor may have been that leaner dialysis patients tend to have more cardiovascular disease, extracellular fluid excess and higher mortality [59].

\section{HOW SHOULD ARTERIAL ELASTICITY BE MEASURED?}

We have previously suggested that the Lok's criteria [49] for predicting maturation failure are a clinical surrogate for arterial stiffness. A more direct clinical method of assessing arterial elasticity is provided by the standard blood pressure measurement. The high pulse wave velocity of stiff vessels causes reflected arterial waves to return during systole rather than during diastole. This results in a high pulse pressure and high systolic pressure with reduced diastolic pressure. Thus, we found that maturation failure correlated with higher pulse and systolic pressures (Fig. 4) [58]. However, the two variables were not independent risk factors when small artery elasticity index and body mass index were included in a multivariable model. Nevertheless, this suggests that such blood pressure measurements should be considered when patients undergo preoperative access planning.

The CR-2000 device that we used to measure elasticity requires little training and is easy to apply [56-58, 60]. The instrument measures arterial waveforms and uses a modified Windkessel model to analyze the pressure pulse contour. The method is based on analysis of peripheral wave reflections superimposed on the diastolic decay of the basic pressure waveform. Large artery elasticity index reflects changes in the structure and compliance of large arteries, such as the aorta. Small artery elasticity index reflects changes in 

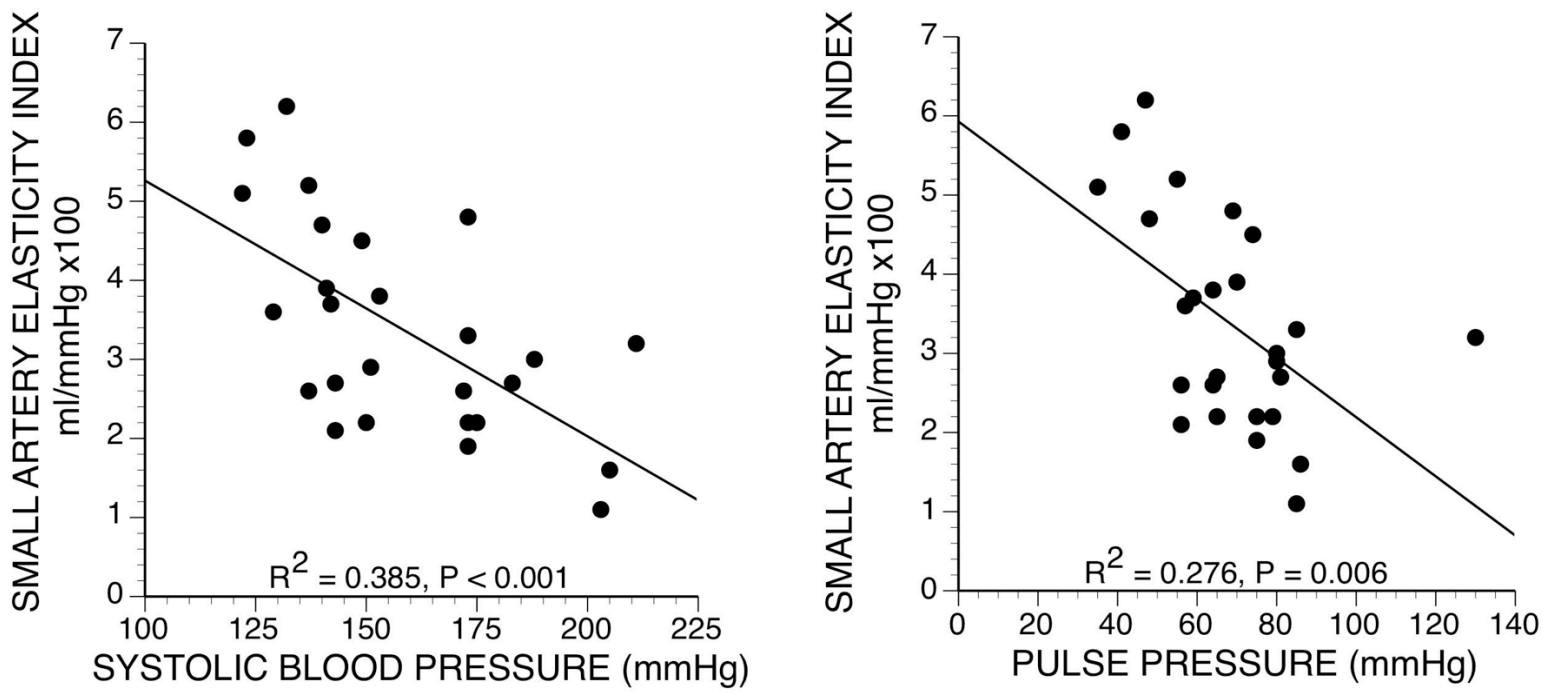

Fig. (4). Relation between small artery elasticity index $v s$ systolic blood pressure and pulse pressure [58].

elasticity of arterioles and the smallest arteries, and includes reflections from branch points in the circulation. Small artery elasticity index is a more sensitive measure of vascular disease than large artery elasticity [61], and may detect vascular changes before they become irreversible, whereas large artery elasticity index reflects changes that may already be irreversible. The higher sensitivity of small artery elasticity in detecting vascular disease may explain why it was a better predictor of maturation [58].

The role of the modified Windkessel model in assessing vascular health is controversial. Some have supported the model [56, 62-64], whereas others have argued that the model has significant shortcomings $[39,41,65,66]$. For example, the Windkessel model assumes that a pulse is transmitted instantaneously throughout the arterial circuit, which is an oversimplification. Some have criticized the model as being overly influenced by local vessel characteristics in a limb, suggesting that it may not be a true assessment of overall vascular health [66]. However, all models involve simplifications of reality that hopefully incorporate essential physiology so that they provide clinically valid analyses. In this case, evaluation of vessels for fistula creation is primarily a local assessment, so this property should be an advantage. In any case, we found that the method correlated with clinical markers of arterial stiffness (systolic blood pressure and pulse pressure) (Fig. 4), and most important of all, it correlated with fistula outcome [58].

\section{HOW SHOULD LOW ELASTICITY BE TREATED?}

If the vasculopathy of ESRD plays an important role in fistula maturation failure, then treatments that prevent or reverse vessel stiffness should be considered. For example, the metabolic bone disease of ESRD is associated with arterial stiffness [8, 67, 68]. There has been concern that treatment with calcium containing phosphorus binders may contribute to calcification of vessels. Takenaka et al. found that pulse wave velocity decreased in 15 hemodialysis patients when they were switched from calcium carbonate to sevelamer for phosphorus binding [69]. Thus, it seems prudent to control calcium and phosphorus plasma levels, and avoid calcium containing phosphorus binders if feasible. Inhibitors of vascular calcification also have potential to be useful [70].

Blood pressure medications that improve arterial elasticity should be emphasized [40, 71, 72]. If nitric oxide deficiency and endothelial dysfunction are major contributors to the vasculopathy of ESRD, then it makes sense to directly address this problem (Fig. 2). For example, Sildenafil enhances the effect of nitric oxide by inhibiting phosphodiesterase-5, which degrades cGMP; persistent action of cGMP thereby promotes continued vascular smooth muscle relaxation. This effect explains why sildenafil lowers arterial blood pressure and improves measures of vascular health in systemic arteries. For example, sildenafil reduces pulse wave velocity in patients with hypertension or coronary artery disease [73, 74]. In a pilot study [75], we have found that one $50 \mathrm{mg}$ dose of sildenafil increased small artery elasticity index and decreased pulse wave velocity. Moreover, patients with the lowest baseline elasticity had the largest increase after taking sildenafil. Other medications that improve endothelial function such as endothelin antagonists [8], and antioxidants such as Nacetylcysteine [76], may also be helpful. Blockade of the renin-angiotensin-aldosterone system is associated with improved arterial elasticity. For example, spironolactone is associated with a reduction in arterial stiffness in chronic kidney disease [77].

\section{CONCLUSION}

We can conclude that vessel elasticity (stiffness) does indeed affect fistula maturation. Poor elasticity is an important step in the cascade of events that leads to maturation failure (Fig. 1). Moreover, arteriosclerosis is not only a major impediment to fistula maturation, but is the common pathway that leads to the major cause of death in ESRD: cardiovascular disease. Since dilatation of both the artery and vein is necessary for fistula maturation, both vessels appear to be important in predicting fistula maturation and preventing maturation failure. However, it is not enough to establish a statistical relationship between a preoperative test and maturation outcome. Such tests must satisfy statistical criteria, such as high sensitivity and 
specificity, and provide adequate positive and negative predictive values - criteria that to date have rarely been addressed in this emerging field. Moreover, in order for a test to be widely adopted clinically, it should be fast and easy to apply - a criterion that many tests described herein may not meet. Finally, the uremic milieu has many interacting elements of abnormal physiology that together may make prevention and treatment of maturation failure particularly challenging. Thus, the benefit and optimum criteria for evaluating and treating vascular elasticity remain to be established.

\section{CONFLICT OF INTEREST}

The author confirms that this article content has no conflict of interest.

\section{ACKNOWLEDGEMENTS}

Declared none.

\section{REFERENCES}

[1] Al-jaishi AA, Oliver MJ, Thomas SM, et al. Patency rates of the arteriovenous fistula for hemodialysis: A systematic review and meta-analysis. Am J Kidney Dis 2014; 63: 464-78.

[2] Kakkos SK, Andrzejewski T, Haddad JA, et al. Equivalent secondary patency rates of upper extremity Vectra Vascular Access Grafts and transposed brachial-basilic fistulas with aggressive access surveillance and endovascular treatment. J Vasc Surg 2008; 47: 407-14.

[3] Lok CE, Sontrop JM, Tomlinson G, et al. Cumulative patency of contemporary fistulas versus grafts (2000-2010). Clin J Am Soc Nephrol 2013; 8: 810-8

[4] Dember LM, Beck GJ, Allon M, et al. Effect of Clopidogrel on early failure of arteriovenous fistulas for hemodialysis. J Am Med Assoc 2008; 299: 2164-71.

[5] Remuzzi A, Ene-Lordache B. Novel paradigms for dialysis vascular access: Upstream hemodynamics and vascular remodeling in dialysis access stenosis. Clin J Am Soc Nephrol 2013; 8: 218693.

[6] Lee T. Novel Paradigms for dialysis vascular access: Downstream vascular biology - Ist there a final common pathway? Clin J Am Soc Nephrol 2013; 8: 2194-201.

[7] Blacher J, Guerin AP, Pannier B, et al. Arterial calcifications, arterial stiffness, and cardiovascular risk in end-stage renal disease. Hypertension 2013; 38: 938-41.

[8] Chue CD, Townend JN, Steeds RP, Ferro CJ. Arterial stiffness in chronic kidney disease: causes and consequences. Heart 2010; 96: $817-23$.

[9] London GM, Marchais SJ, Guerin AP, Metivier F, Adda H. Arterial structure and function in end-stage renal disease. Nephrol Dial Transplant 2002; 17: 1713-24.

[10] Pannier B, Guerin AP, Marchais SJ, Metivier F, London GM. Arterial structure and function in end-stage renal disease. Art Res 2007; 1: 79-88.

[11] Allon M, Litovsky S, Young CJ, et al. Medial fibrosis, vascular calcification, intimal hyperplasia, and arteriovenous fistula maturation. Am J Kidney Dis 2011; 58: 437-43.

[12] Briet $\mathrm{M}$, Bozec E, Laurent $\mathrm{S}$, et al. Arterial stiffness and enlargement in mild-to-moderate chronic kidney disease. Kidney Int 2006; 69: 350-7.

[13] Ku YM, Kim YO, Kim JI, et al. Ultrasonographic measurement of intima-media thickness of radial artery in predialysis ureaemic patients: Comparison with histological examination. Nephrol Dial Transplant 2006; 21: 715-20.

[14] Muntner P, He J, Hamm L, Loria C, Whelton PK. Renal insufficiency and subsequent death resulting from cardiovascular disease in the United States. J Am Soc Nephrol 2002; 13: 745-53.
[15] Cameron JD, Cruickshank JK: Glucose, insulin, diabetes and mechanisms of arterial dysfunction. Clin Exp Pharmacol Physiol 2007; 34: 677-82.

[16] London GM, Marchais SJ, Guerin AP, Pannier B. Arterial stiffness: pathophysiology and clinical impact. Clin Exp Hypertens 2004; 26; 689-99.

[17] Glassock RJ, Pecoits-Filho R, Barberato SH. Left ventricular mass in chronic kidney disease and ESRD. Clin J Am Soc Nephrol 2009; 4: S79-91.

[18] Henrich WL. Optimal cardiovascular therapy for patients with ESRD over the next several years. Clin J Am Soc Nephrol 2009; 4: S106-9.

[19] McCullough PA. Coronary artery disease. Clin J Am Soc Nephrol 2007; 2: 611-6.

[20] Ritz E, Bommer J. Cardiovascular problems on hemodialysis: current deficits and potential improvement. Clin J Am Soc Nephrol 2009; 4: S71-8.

[21] Feinfeld DA, Bastista R, Mir R, Babich D. Changes in venous histology in chronic hemodialysis patients. Am J Kidney Dis 1999; 34: 702-5.

[22] Lee T, Chauhan V, Krishnamoorthy M, et al. Severe venous neointimal hyperplasia prior to dialysis access surgery. Nephrol Dial Transp 2011; 26: 2264-70.

[23] Lee T, Safdar N, Mistry MJ, et al. Preexisting venous calcification prior to dialysis vascular access surgery. Sem Dial 2012; 25: 592-5.

[24] Wasse H, Rivera AA, Huang R, et al. Increased plasma chymase concentration and mast cell expression in venous neointimal lesions of patients with CKD and ESRD. Sem Dial 2011; 24: 688-93.

[25] Baylis C. Nitric Oxide deficiency in chronic renal disease. Eur J Clin Pharmacol 2006; 62: 123-30.

[26] Gunthner T, Jankowski V, Kretschmer A, et al. Endothelium and vascular smooth muscle cells in the context of uremia. Sem Dial 2009; 22; 428-32.

[27] Passauer J, Pistrosch F, Bussemaker E. Nitric oxide in chronic renal failure. Kidney Int 2005; 67: 1665-7.

[28] Passauer J, Pistrosch F, Bussemaker E, Lassig G, Herbrig K, Gross $P$. Reduced agonist-induced endothelium-dependent vasodilation in uremia is attributable to an impairment of vascular nitric oxide. $\mathrm{J}$ Am Soc Nephrol 2005; 16: 959-65.

[29] Vallance P, Leone A, Calver A, Collier J, Moncada S Accumulation of an endogenous inhibitor of nitric oxide synthesis in chronic renal failure. Lancet 1992; 339: 572-5.

[30] Guzman RJ, Abe K, Zarins CK. Flow-induced arterial enlargement is inhibited by suppression of nitric oxide synthase activity in vivo. Surgery $1997 ; 122: 273-9$.

[31] Kinlay S, Creager MA, Fukumoto M, et al. Endothelium-derived nitric oxide regulates arterial elasticity in human arteries in vivo. Hypertension 2001; 38: 1049-53.

[32] Ghiadoni L, Cupisti A, Huang Y, et al. Endothelial dysfunction and oxidative stress in chronic renal failure. J Nephrol 2004; 17: 512-19.

[33] Dixon BS. Why don't fistulas mature? Kidney Int 2006; 70: 1413 22.

[34] Roy-Chaudhury P, Spergel LM, Besarab A, Asif A, Ravani P. Biology of arteriovenous fistula failure. J Nephrol 2007; 20: 15063 .

[35] Silva MB, Hobson RW, Pappas PJ, et al. A strategy for increasing use of autogenous hemodialysis access procedures: Impact of preoperative noninvasive evaluation. J Vasc Surg 1998; 27:302-7, discussion 307-8.

[36] Peterson WJ, Barker J, Allon M. Disparities in fistula maturation persist despite preoperative vascular mapping. Clin J Am Soc Nephrol 2008; 3: 437-41.

[37] Planken RN, Leiner T, Tordoir JHM. Forearm venous distensibility measurements with ultrasound techniques are poorly reproducible (letter). Am J Kidney Dis 2007; 49: 347.

[38] Weitzel WF. Preoperative hemodialysis fistula evaluation: Angiography, ultrasonography and other studies, are they useful? In: Ronco C, Cruz DN, Eds. Hemodialysis - from basic research to clinical trials. Contrib Nephrols. Karger: Basel, Switzerland 2008; vol 161: pp. 23-9.

[39] O'Rourke MF, Staessen JA. Clinical applications of arterial stiffness. Am J Hypertens 2002; 15: 426-44.

[40] Weber T, Auer J, Eisserer G, Berent R, Eber B, O'Rourke MF. Arterial stiffness and cardiovascular drugs. Curr Pharm Design 2003; 9: 1049-63. 
[41] DeLoach SS, Townsend RR. Vascular stiffness: Its measurement and significance of epidemiologic and outcome studies. Clin J Am Soc Nephrol 2008; 3: 184-92.

[42] Planken RN, Keuter XH, Kessels AG, Hoeks AP, Leiner T, Tordoir $\mathrm{JH}$. Forearm cephalic vein cross-sectional are changes at incremental congestion pressures: Towards a standardized and reproducible vein mapping protocol. J Vasc Surg 2006; 44: 353-8.

[43] Malovrth M. Native arteriovenous fistula: Preoperative evaluation. Am J Kidney Dis 2002; 39: 1218-25.

[44] Kim JT, Chang WH, Oh TY, Jeong YK. Venous distensibility as a key factor in the success of arteriovenous fistulas at the wrist. Ann Vasc Surg 2011; 25: 1094-8.

[45] Jemcov TK. Morphologic and functional vessels characteristics assessed by ultrasonography for prediction of radiocephalic fistula maturation. J Vasc Access 2013; 14: 356-63.

[46] Van Bemmelen PS, Kelly P, Blebea J. Improvement in the visualization of superficial arm veins being evaluated for access and bypass. J Vasc Surg 2005; 42: 957-62.

[47] Van der Linden J, Lameris TW, van den Meiracker AH, de Smet AAEA, Blankestijn P, van den Dorpel MA. Forearm venous distensibility predicts successful arteriovenous fistula. Am J Kidney Dis 2006; 47: 1013-9.

[48] Biswas R, Patel P, Park DW, et al. Venous elastography: Validation of a novel high-resolution method for measuring vein compliance using finite element analysis. Sem Dial 2010 23: 105-9.

[49] Lok CE, Allon M, Moist L, Oliver MJ, Shah H, Zimmerman D. Risk equation determining unsuccessful cannulation events and failure to maturation in arteriovenous fistulas (REDUCE FTM I). J Am Soc Nephrol 2006; 17: 3204-12.

[50] Ichihara A, Yamashita N, Takemitsu T, et al. Cardio-ankle vascular index and ankle pulse wave velocity as a marker of arterial fibrosis in kidney failure treated by hemodialysis. Am J kidney Dis 2008; 52: $947-55$.

[51] Dember LM, Imrey PB, Beck GJ, et al. Objectives and design of the hemodialysis fistula maturation study. Am J Kidney Dis 2013; 63: 104-12.

[52] Weitzel WF, Rubin JM, Xie H, O'Donnell M. Renal advances in ultrasound elasticity imaging: Measuring the compliance of arteries and kidneys in end-stage renal disease. Blood Purif 2005; 23: 10-7.

[53] Sorace AG, Robbin ML, Umphrey H, et al. Ultrasound measurement of Brachial artery elasticity before hemodialysis access placement: A pilot study. J Ultrasound Med 2012; 31: 1581-8.

[54] Sollinger D, Mohaupt MG, Wilhelm A, Uehlinger D, Frey FJ, Eisenberger U. Arterial stiffness assessed by digital volume pulse correlates with comorbidity in patients with ESRD. Am J Kidney Dis 2006; 48: 456-63.

[55] Owens CD, Wake N, Kim M, Hentschel D, Conte MS, Schanzer A. Endothelial function predicts positive arterial-venous fistula remodeling in subjects with stage IV and V chronic kidney disease. J Vasc Access 2010; 11: 329-34.

[56] Prisant LM, Resnick LM, Hollenberg SM. Arterial elasticity among normotensive subjects and treated and untreated hypertensive subjects. Blood Press Monit 2001; 6: 233-7.

[57] Cohn JN, Finkelstein S, McVeigh GE, et al. Noninvasive pulse wave analysis for the early detection of vascular disease. Hypertension 1995; 26: 503-8.

[58] Kheda MF, Brenner LE, Patel MJ, et al. Influence of arterial elasticity and vessel dilatation on arteriovenous fistula maturation: A prospective cohort study. Nephrol Dial Transplant 2010; 25: $525-31$.
[59] Peralta CA, Jacobs DR, Katz R, et al. Association of pulse pressure, arterial elasticity, and endothelial function with kidney function decline among adults with estimated GFR $>60$ $\mathrm{mL} / \mathrm{min} / 1.73 \mathrm{~m}^{2}$ : The multi-ethnic study of atherosclerosis (MESA). Am J Kidney Dis 2012; 51: 41-9.

[60] Finkelstein SM, Collins VR, Cohn JN. Arterial vascular compliance response to vasodilators by fourier and pulse contour analysis. Hypertension 1988; 12: 380-7.

[61] Grey E, Bratteli C, Glasser SP, et al. Reduced small artery but not large artery elasticity is an independent risk marker for cardiovascular events. Am J Hypertens 2003; 16: 265-9.

[62] Oliver JJ, Webb DJ. Noninvasive assessment of arterial stiffness and risk of atherosclerotic events. Arterioscler Thromb Vasc Biol 2003; 23: 554-66.

[63] Wilson AM, O’Neal D, Nelson CL, Prior DL, Best JD, Jenkins AJ. Comparison of arterial assessments in low and high vascular disease groups. Am J Hypertens 2004; 17: 285-91.

[64] Woodman RJ, Kingwell BA, Beilin LJ, Hamilton SE, Dart AM, Watts GF. Assessment of central and peripheral arterial stiffness. Am J Hypertens 2005; 18: 249-60.

[65] Izzo JL. Arterial stiffness and the systolic hypertension syndrome. Curr Opin Cardiol 2004; 19: 341-52.

[66] Manning TS, Shykoff BE, Izzo JL. Validity and reliability of diastolic pulse contour analysis (Windkessel Model) in humans. Hypertension 2002; 39: 963-8.

[67] London GM, Guerin AP, Verbeke FH, et al. Mineral metabolism and arterial functions in end-stage renal disease: Potential role of 25-hydroxyvitamin D deficiency. J Am Soc Nephrol 2007; 18: 61320.

[68] Raggi P, Bellasi A, Ferramosca E, Block GA, Muntner P. Pulse wave velocity is inversely related to vertebral bone density in hemodialysis patients. Hypertension 2007; 49: 1278-84

[69] Takenaka T, Suzuki H. New strategy to attenuate pulse wave velocity in haemodialysis patients. Nephrol Dial Transplant 2005; 20: 811-6.

[70] Chen NX, Moe SM. Uremic vascular calcification. J Investig Med 2006; $54: 380-4$

[71] Dudenbostel T, Glasser SP. Effects of antihypertensive drugs on arterial stiffness. Cardiol Rev 2012; 20: 259-63.

[72] Zieman SJ, Melenovsky V, Clattenburg L, et al. Advanced glycation endproduct crosslink breaker (alagebrium) improves endothelial function in patients with isolated systolic hypertension. J Hypertens 2007; 25: 577-83.

[73] Mahmud A, Hennessy M, Feely J. Effect of sildenafil on blood pressure and arterial wave reflection in treated hypertensive men. J Human Hypertens 2001; 15: 707-13.

[74] Vlachopoulos C, Hirata K, O'Rourke MF. Effect of sildenafil on arterial stiffness and wave reflection. Vascular Medicine 2003; 8: 243-8.

[75] Paulson WD, Dubner A, White J, et al. Sildenafil reduces arteria stiffness in ESRD patients treated with hemodialysis (abstract). J Am Soc Nephrol 2012; 23: 599A.

[76] Wittstock A, Burkert M, Zidek W, Tepel M, Scholze A. NAcetylceysteine improves arterial vascular reactivity in patients with chronic kidney disease. Nephron Clin Pract 2009; 112: 184-9.

[77] Edwards NC, Steeds RP, Stewart PM, Ferro CJ, Townend JN Effect of spironolactone on left ventricular mass and aortic stiffness in early-stage chronic kidney disease. J Am Coll Cardiol 2009; 54 $505-12$ 